\title{
Improving the fatigue behaviour of a selectively laser melted aluminium alloy: Influence of heat treatment and surface quality
}

\author{
Nesma T. Aboulkhair ${ }^{\mathrm{a}, \mathrm{b} 1}$, Ian Maskery ${ }^{\mathrm{a}}$, Chris Tuck ${ }^{\mathrm{a}}$, Ian Ashcroft ${ }^{\mathrm{a}}$, and Nicola M. Everitt ${ }^{\mathrm{b}}$ \\ aAdditive Manufacturing and 3D Printing Research Group, Faculty of Engineering, University of Nottingham, \\ Nottingham, NG7 2RD, United Kingdom \\ ${ }^{b}$ Bioengineering Research Group, Faculty of Engineering, University of Nottingham, Nottingham, NG7 2RD, \\ United Kingdom
}

\section{ABSTRACT}

Selective laser melting (SLM) is being widely utilised to fabricate intricate structures used in various industries. Widening the range of applications that can benefit from such promising technology requires validating SLM parts in load bearing applications. Recent studies have mainly focussed on static loading, with minor attention to cyclic loading despite its vital importance in many applications. In this work, the fatigue performance of SLM AlSi10Mg was investigated considering the effects of surface quality and heat treatment. Compared to heat treatment, machining the samples played a minor role in improving the fatigue behaviour. This is potentially attractive to industries interested in latticed structures and topology-optimised parts where post-processing machining is not feasible. The characteristically fine microstructure in the as-built samples provided good fatigue crack propagation resistance but none of them survived nominal fatigue life of $3 \times 10^{7}$ cycles within the maximum stress range of 63-220 MPa. A specially-tailored heat treatment increased the material's ductility, significantly improving its fatigue performance. At $94 \mathrm{MPa}$, the heat-treated samples survived beyond the nominal fatigue life, outperforming the reference cast material. The combined effect of machining and heat treatment yielded parts with far superior fatigue properties, promoting the material for a wider range of applications.

Keywords: Additive manufacture; selective laser melting; Aluminium alloys; microstructure; fatigue; heat treatment.

\footnotetext{
${ }^{1}$ E-mail: nesma.aboulkhair@nottingham.ac.uk
} 


\section{INTRODUCTION}

Additive manufacturing (AM) via selective laser melting (SLM) enables the fabrication of geometrically complex structures, providing various industrial sectors with a range of opportunities, such as light-weighting and added functionality [1,2]. Drastic weight reduction can be achieved by several methods, such as topology optimisation [3,4] or replacing a bulk of solid material with latticed structures [5, 6]. AM has the potential to fulfil demands for cost and design-to-manufacturing time reduction through saving on raw materials and replacing a series of production processes with a single step process. AM, also, promotes the possibility of producing cost-effective customised products $[7,8]$. Parts produced using AM are already widely used in various fields, such as the medical [9], automotive, and aerospace industries [7]. Fabricating load bearing parts using SLM, such as automotive power trains, turbine components [10], or aerospace components [11], is becoming more commonplace, therefore studying their mechanical performance is gaining further attention to cope with the widely expanding popularity for the process [12] and confirm its credibility. Recent studies have mainly considered the static tensile properties of the parts $[10,13,14]$, with less attention so far to fatigue performance, as stated by [15]. Fatigue behaviour of parts is one of the important properties to be considered when evaluating a material for application in industry.

SLM parts can suffer from cracks [16], pores [17], poor surface roughness, and high residual stresses [18] arising from the high energy density \{energy density $=$ laser power / (scan speed $*$ hatch spacing * layer thickness) [19]\} induced by the process and subsequent fast solidification [20, 21] and high thermal gradients. SLM materials also have distinctive microstructures [22] when compared to conventionally processed materials. All these features affect the mechanical properties of SLM parts and differentiate them from those manufactured by conventional processes [13]. Although the porosity of SLM parts, processed with optimised parameters, does not drastically reduce the load bearing area and might not be therefore sufficient to reduce the stiffness of the material in load bearing applications [13], this is not the case for fatigue performance [21], which is strongly affected by the presence of pores [23]. The probability of failure under cyclic loading increases as the fraction or size of defects increases since fatigue cracks nucleate at these defects [15, 20, 24]. The sensitivity 
of fatigue properties to surface defects, accentuated by the poor surface roughness, has been widely reported for SLM titanium alloys [20, 25, 26] and stainless steel [27]. Brandl et al. [15] investigated the fatigue behaviour of SLM AlSi10Mg samples with machined surfaces. Mower and Long [28], on the other hand, tested SLM AlSi10Mg samples with as-built and polished surfaces and reported a poorer fatigue performance in both cases, compared to the results of Brandl et al [15]. It is important to note that these two studies used different SLM systems and processing parameters that can lead to different levels of porosity in the produced samples. Therefore, it cannot be confirmed that the surface quality of SLM AlSi10Mg plays a major role in controlling the fatigue performance.

Several approaches to improve the fatigue behaviour of SLM parts have been reported in the literature. For instance, the fatigue endurance limit can be doubled through reducing the surface roughness for Ti-6Al-4V [9, 29]. Siddique et al. [30] and Shiomi et al. [18] agreed that the use of a heated platform $\left(200{ }^{\circ} \mathrm{C}\right)$ or using double scan strategies diminished the residual stresses. Nevertheless, it has been previously reported that heating the platform does not affect the mean fatigue strength of the material but rather reduce the scatter in results [15]. Riemer et al. [27], working on stainless steel, reported stress-relief, through heat treatment or hot isostatic pressing, to yield fatigue properties that were the same as, or even better than those of, conventionally manufactured samples. Edwards and Ramulu [20] recommended peening to induce compressive residual stresses at the surface since their Ti-6Al-4V SLM parts had tensile residual stresses. Post manufacturing heat treatment is a means of reducing the residual stresses in SLM parts. Although heat treating SLM parts is usually guided by the procedures laid out for conventional materials, it is important to note that this might not be generally applicable due to the difference in starting microstructure [21]. The authors of this paper have previously reported [31] an investigation into the heat treatment of SLM AlSi10Mg using a conventional T6 procedure, and observed material softening, rather than the hardening effect that takes place after T6 heat treatment of a conventionally processed AlSi10Mg. They, further, developed an understanding of how to tailor the heat treatment procedure for SLM parts to achieve a particular mechanical response. 
AlSi10Mg is commonly used in the automotive industry for its high specific strength [24], in applications where fatigue performance is also critical [32]. Therefore, this paper investigates the fatigue behaviour of SLM AlSi10Mg and determines the effect of the sample's surface quality and heat treatment on the material's performance under cyclic loading. This paper aims to define the importance of the surface quality as a factor influencing the fatigue behaviour of SLM parts made from $\mathrm{Al}$ alloys and find an alternative to post process machining that would enhance the fatigue performance. This alternative will further promote the feasibility of using AM processes for lightweighting purposes where a geometrically complex structure needs to be fabricated without the capability of post-process machining as in the case of latticed structures and topology optimised parts.

\section{MATERIALS \& METHODS}

AlSi10Mg powder supplied by LPW Technology was used in this study, the properties of the powder can be found in [17]. A Renishaw AM250 SLM machine was used to fabricate two batches of standard fatigue test specimens with reduced gauge sections (Figure 1) with continuous radius of curvature between the grip ends, as per ASTM standard E466 [33]. Each batch of samples was made up of 36 samples. The samples had a $6 \mathrm{~mm}$ minimum diameter and a $36.8 \mathrm{~mm}$ gauge length. The processing parameters employed are shown in Table 1. The layer thickness is the thickness of each layer of powder deposited prior to the laser scan. The scan speed is the speed the laser beam rasters across the powder layer, which is dictated by the point distance and the exposure time at each point. The hatch spacing is the offset between two adjacent scans. The chessboard scan strategy is the same as the island scan strategy described in [22]. The process parameters used were optimised to produce parts with minimal porosity (below $0.5 \%$ ) and a relatively small layer thickness was used to minimise surface defects and irregularities. The build platform was maintained at $180^{\circ} \mathrm{C}$ during processing to minimize residual stresses [30] and scatter in fatigue data [15]. The machine is equipped with a Ybfibre laser $(\lambda=1064 \mathrm{~nm})$ and the spot size of the laser beam focused at the powder bed is $70 \mu \mathrm{m}$. The machine processes under argon atmosphere with an oxygen content below $0.09 \%$. 

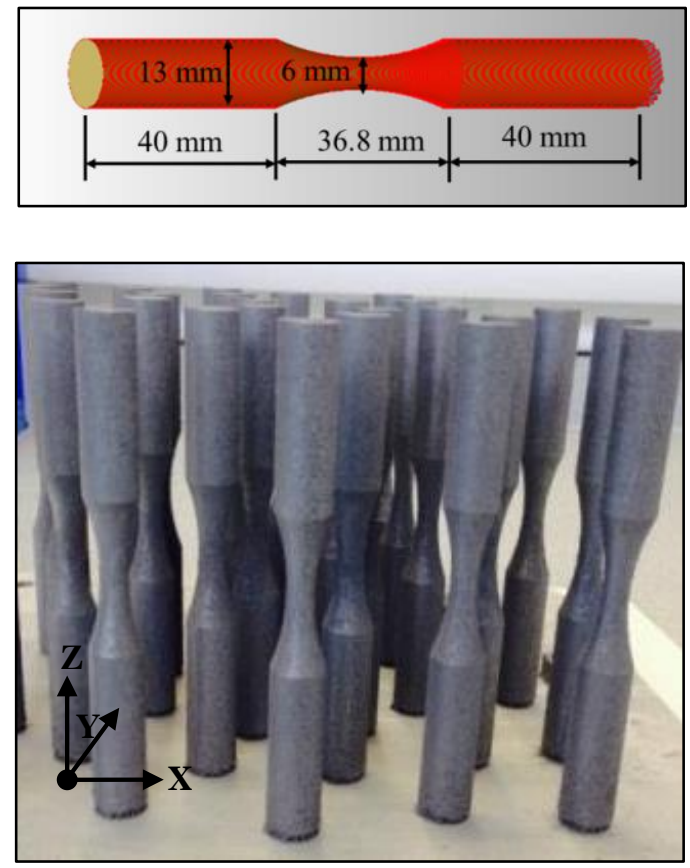

Figure 1: Fatigue samples fabricated using SLM with the build direction parallel to the Z-axis.

Table 1: Processing parameters using Renishaw AM250 to produce near fully dense fatigue samples.

\begin{tabular}{|c|c|c|c|c|}
\hline Laser power & Layer thickness & Scan speed & Hatch spacing & Scan strategy \\
\hline $200 \mathrm{~W}$ & $25 \mu \mathrm{m}$ & $570 \mathrm{~mm} / \mathrm{s}$ & $80 \mu \mathrm{m}$ & Chessboard \\
\hline
\end{tabular}

Batch 1 was tested without machining and Batch 2 was machined by turning to reduce the surface roughness; machining allowance was taken into consideration when building the samples by accounting for extra material removal (1 $\mathrm{mm}$ in diameter). The surface of the sample before and after machining was imaged using a Hitachi TM3030 scanning electron microscope (SEM), equipped with a backscatter electron detector operating at $15 \mathrm{kV}$, to determine the effect of machining on the surface quality. Also, a Mitutoyo Surftest SV-600 was used to measure the surface roughness $\left(R_{a}\right)$ of the samples with and without machining. Half the samples in each batch were heat-treated following a conventional $\mathrm{T} 6$ procedure. The samples were solution heat treated for $1 \mathrm{hr}$ at $520^{\circ} \mathrm{C}$ followed by water quenching to room temperature and then aged for $6 \mathrm{hrs}$ at $160^{\circ} \mathrm{C}$. This was previously shown by the authors [31] to provide the material with increased ductility. As-built and heat-treated samples were cross-sectioned, polished, and etched using Keller's reagent [34] to reveal their microstructures. 
These were imaged using a Nikon Eclipse LV100 ND optical microscope and a Philips XL30 SEM equipped with a secondary electron detector operating at $20 \mathrm{kV}$.

Uniaxial fatigue tests were conducted in load-controlled mode following ASTM standard E466 [33]. Before testing, the machined samples were inspected visually using optical microscopy to ensure they were free of abnormalities, such as cracks or undercuts. The specimens were also cleaned with ethanol prior to testing to remove any surface dirt or oils. An Instron 8801 servo-hydraulic fatigue testing machine with a $100 \mathrm{kN}$ load cell was used for the tests. Tests were conducted in air at room temperature (approximately $21^{\circ} \mathrm{C}$ and $30 \%$ relative humidity). The cyclic loading followed a sine wave with a frequency of $30 \mathrm{~Hz}$. The effect of frequency variation when testing $\mathrm{Al}$ alloys for fatigue behaviour is reported to be insignificant [35]. In the axial fatigue loading, the stress fluctuated between maximum $\left(\sigma_{\max }\right)$ and minimum $\left(\sigma_{\min }\right)$ stress values, with a stress ratio $\left(\mathrm{R}=\sigma_{\min } / \sigma_{\max }\right)$ of 0.1 . The samples were loaded until failure or until nominal fatigue life of $3 \times 10^{7}$ was reached, the surviving samples being identified as run outs. Six maximum stress levels were investigated ranging between $20 \%$ and $70 \%$ of the ultimate tensile strength (UTS) of the material (320 MPa [13]) with $10 \%$ increments, testing three samples at each stress level from each batch of specimens (as-built, machined, heat-treated, and machined and heat-treated). Fracture surfaces of the samples were imaged using a Philips XL30 SEM. The fracture surfaces were also cross-sectioned along the normal plane, polished, etched, and imaged using the optical microscope.

\section{RESULTS}

\subsection{Surface quality of the test specimens}

The surface morphology of the fatigue samples in their as-built condition without post-processing machining can be seen in Figure 2 (a). Irregular surface features, such as balling and satellites [36], were observed. These surface defects are thought to decrease the fatigue strength of SLM parts [26]. The surface roughness $\left(R_{a}\right)$ of the as-built samples was $17.1 \pm 0.9 \mu \mathrm{m}$. In comparison to the as-built samples, post-process machining eliminated all evidence of balling and satellites, as can be seen in Figure 2 (b). The machined surface shows the machining marks from turning as well as some surface 
porosity that was only clearly revealed after machining. The surface roughness $\left(R_{a}\right)$ of the machined samples was $0.62 \pm 0.02 \mu \mathrm{m}$, demonstrating the significantly reduced surface roughness.

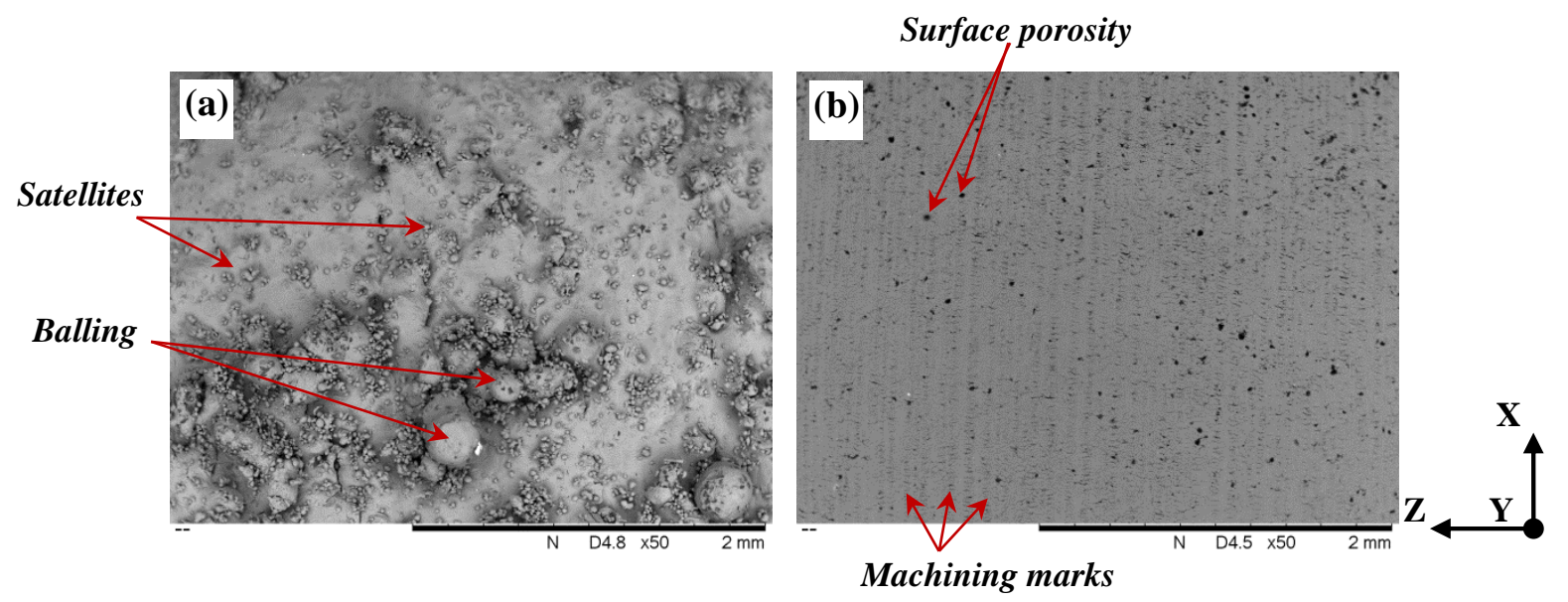

Figure 2: Surface morphology of the sides of (a) an as-built fatigue sample and (b) a sample with machined surface (surface parallel to the build direction). These images were taken from the samples' shoulders.

\subsection{Microstructure of SLM material and the effect of heat treatment}

A part fabricated by SLM is made up of overlapping scan tracks [36] in both the vertical and horizontal directions fused together through metallurgical bonding by re-melting and solidification. Microscopic examination revealed the stacked layers in the samples, as shown in Figure 3 (a) (XZ and YZ planes). Figure 3 (b) shows the change in microstructure upon heat treatment, where spherodisation of Si occurred.

The microstructure of the as-built material is divided into three zones; namely, melt pool core, melt pool boundary, and heat affected zone $[17,22]$. Each scan track is outlined by the melt pool boundary that has a coarser microstructure, along with being Al-rich, as demonstrated by having the lighter shade in the optical micrograph in Figure 3 (a). This distribution of the chemical elements has been previously confirmed using energy dispersive X-ray diffraction by the authors in [31]. Cellulardendritic solidification has been previously reported for SLM AlSi10Mg [22]. The cellular grains at the melt pool core were equiaxed, whereas those at the melt pool boundary were elongated along the direction of the thermal gradient (Figure 3 (a)). Due to the fast rate at which the material solidifies [22], Si dendrites segregated on the boundaries of the columnar $\alpha$-Al along the build direction, as shown in Figure 3 (c). Grains in the XY plane, perpendicular to the build direction, were equiaxed, as can be seen in Figure 3 (d). 


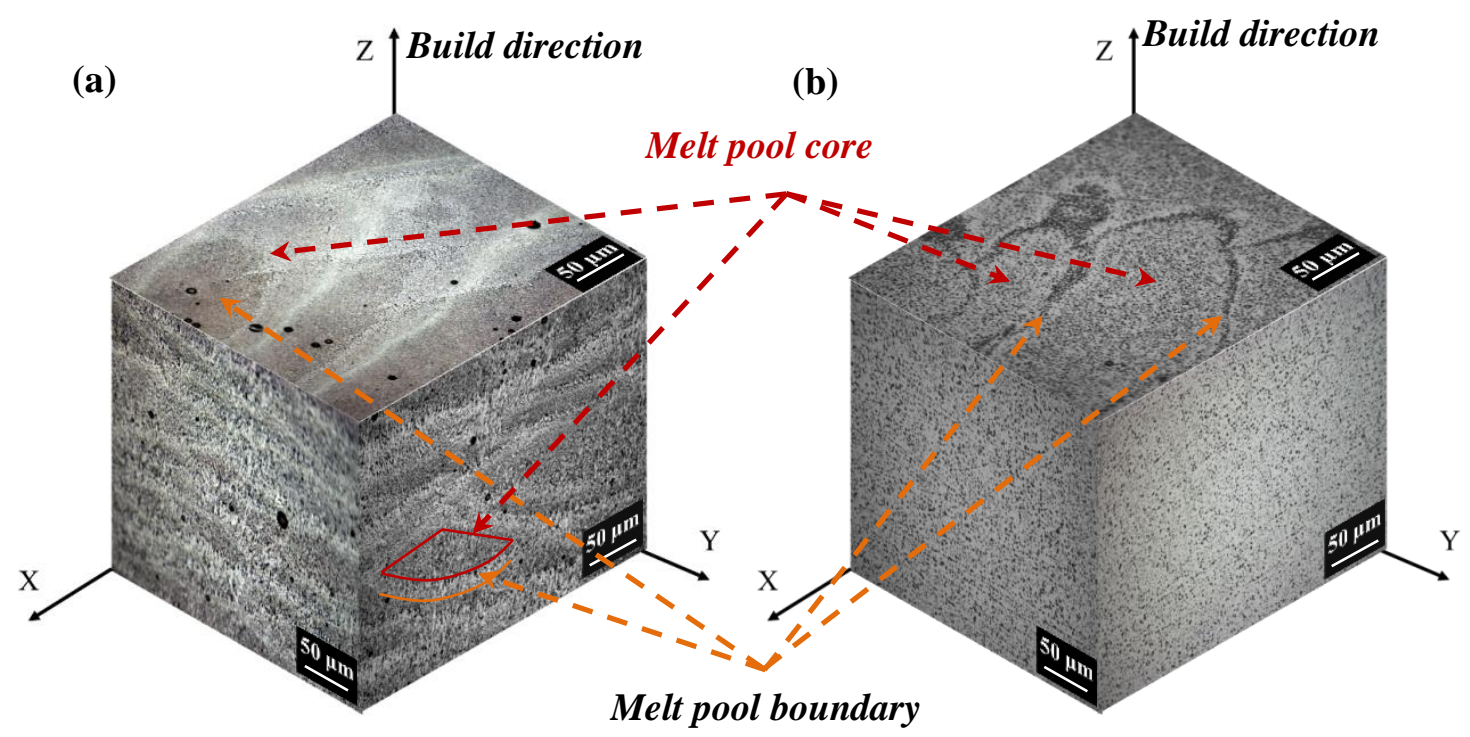

Inter-dendritic Si segregated on the columnar Al boundaries
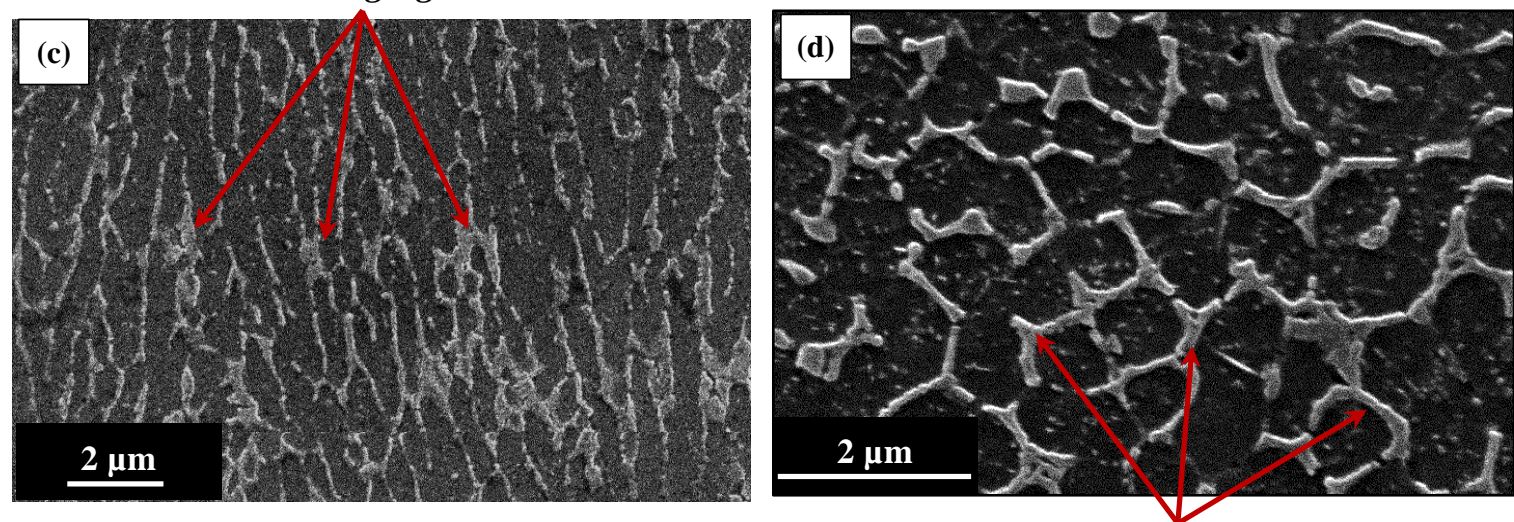

Inter-dendritic Si segregated on the equiaxed Al boundaries

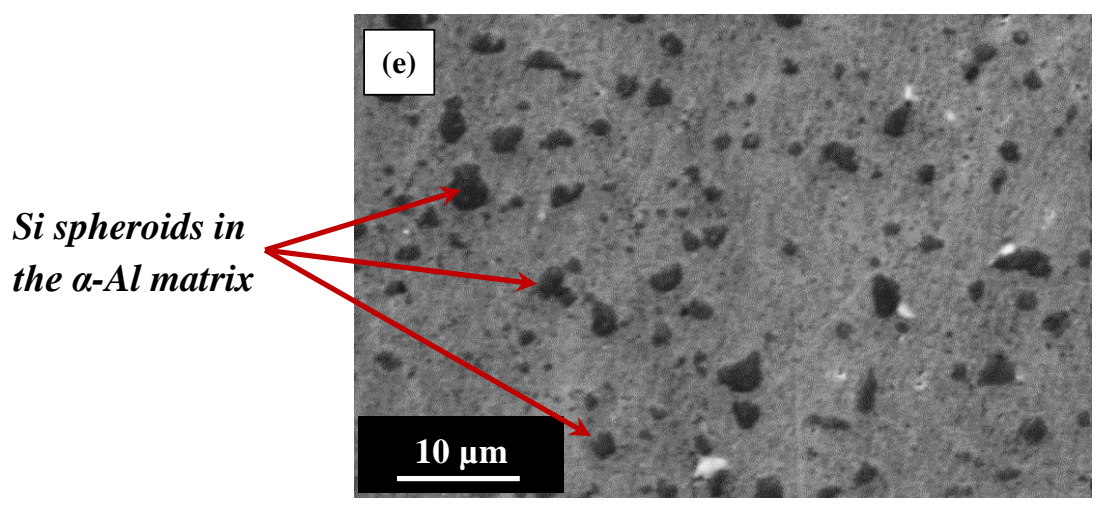

Figure 3: The microstructure of (a) as-built material, (b) heat-treated material, (c) elongated $\alpha$-Al as seen on the $\mathrm{XZ}$ plane in the as-built material, (d) equiaxed $\alpha$-Al grains as seen on the $\mathrm{XY}$ plane in the as-built material, and (e) $\mathrm{Si}$ spheroids in the $\alpha$-Al matrix after T6 heat treatment. These images were obtained from cross-sectioning the shoulders of as-built and heat-treated samples.

The heat treatment involves homogenising the microstructure to obtain a supersaturated solid solution that is maintained by rapid quenching, after which the material is artificially aged. This heat treatment modifies the microstructure of the material significantly, as has been previously demonstrated by the 
authors [31]. Figure 3 (e) shows that Si diffused to form particles, or spheroids, in the $\alpha$-Al matrix, which is known as spheroidisation transformation. The presence of spheroidal particles in the microstructure has been reported [15] to reduce fatigue crack initiation. This heat treatment has been reported to enhance the material's ductility as a result of its softening [31]. Also, Brandl et al. [15] reported that spherodisation eliminates the microstructural variation across the material, i.e. features distinctive of melt pool core, boundary, or heat affected zones, resulting in a more homogeneous microstructure.

\subsection{Stress-life (S-N) curves}

The S-N curve of the fatigue samples in Figure 4 shows the averaged results for the maximum stress and the number of cycles to failure. The observed results were analysed quantitatively by fitting the fatigue data (nominal stress amplitude and number of cycles to failure) with a Basquin fit [37], as shown in Figure 5. When the fatigue data, nominal stress amplitude $\left(S_{a}\right)$ and number of cycles to failure $\left(N_{f}\right)$, is fitted with a Basquin fit, it can then be presented in the form of $S_{a}=A\left(N_{f}\right)^{B}$. When the data is plotted on a log-log scale and fitted with a linear regression, $\log (A)$ can be determined as the intercept of the linear fit and its gradient represents $B$. These parameters were extracted from the plots in Figure 5 and presented in Table 2.

None of the as-built samples in this study, where the lowest maximum stress level examined was $63 \mathrm{MPa}$, exceeded the pre-defined run out limit of $3 \times 10^{7}$ cycles. At the stress of $63 \mathrm{MPa}$, the samples survived for an average of just over $7.6 \times 10^{6}$ cycles. There has been evidence that the fatigue life of SLM samples from materials other than aluminium in their as-built condition is shorter than those with machined surfaces [26]. This has been attributed to the poor surface roughness common in the as-built samples, which favours fatigue crack initiation. From the results in Figure 4, presenting the S$\mathrm{N}$ data for the samples with and without machining, it can be deduced that this cannot be generalised over the range of stress levels. For instance, the fatigue life of both as-built and machined samples was similar at the higher maximum stress levels, but at maximum stress levels below $157 \mathrm{MPa}$ some of the machined samples started to survive the pre-defined $3 \times 10^{7}$ cycles cut off limit, with all the samples surviving at $63 \mathrm{MPa}$. This suggests that machining the samples improves the fatigue life 
principally at lower stress levels with a far less significant effect observed at higher stress levels. This is potentially because fatigue life is initiation dominated at low stress and propagation dominated at high stress, with surface roughness having the greater effect on fatigue initiation. This was also evident in Figure 5 (a), as there was not much change in the fatigue behaviour of the samples after machining for the range of nominal stress amplitude between 42 and $99 \mathrm{MPa}$. This is further supported quantitatively by the Basquin fit parameters in Table 2 that were only slightly altered to have a larger gradient. This is due to all the samples surviving the cut off limit at nominal stress amplitude of $28 \mathrm{MPa}$. In addition to not improving the fatigue performance at the higher stress levels, machining the samples led to a wider range of variability in the material's performance under cyclic loading since some of the samples survived the pre-defined cut off limit of $3 \times 10^{7}$ cycles and others failed within the range of $1 \times 10^{5}$ to $3 \times 10^{5}$ cycles. This wide range of variability negatively affects the reliability of the machined samples.

An alternative approach that could be adopted to enhance the fatigue life of Al alloys is by heat treatment, as described in [15]. This is confirmed in this work by comparing the S-N curves of samples heat-treated using the procedure described in [31] to as-built samples, as seen in Figure 4 and Figure 5 (a). These curves show that the heat treatment has significantly improved the fatigue performance of the samples at all tested stress levels, with the best improvement at the lower stress levels. All of the heat-treated samples survived the pre-defined cut off limit at a maximum stress of $94 \mathrm{MPa}$. The gradient of the Basquin fit was reduced from (-0.22) to (-0.15) after heat treatment, indicating the significantly improved performance alongside the overall shift to a higher cycles range with larger improvement at the lower stress levels.

The combined effect of heat treatment and machining led to an overall enhancement in the fatigue behaviour of the samples at all tested stress levels, as demonstrated in Figure 4 and Figure 5 (b). All the samples in this batch survived the cut off limit at a maximum stress of $126 \mathrm{MPa}$. The gradient of the linear fit for this batch of samples was very close to that of the as-built samples with a larger intercept, indicating an almost equal improvement at all stress levels until the samples start to survive the cut off limit. 


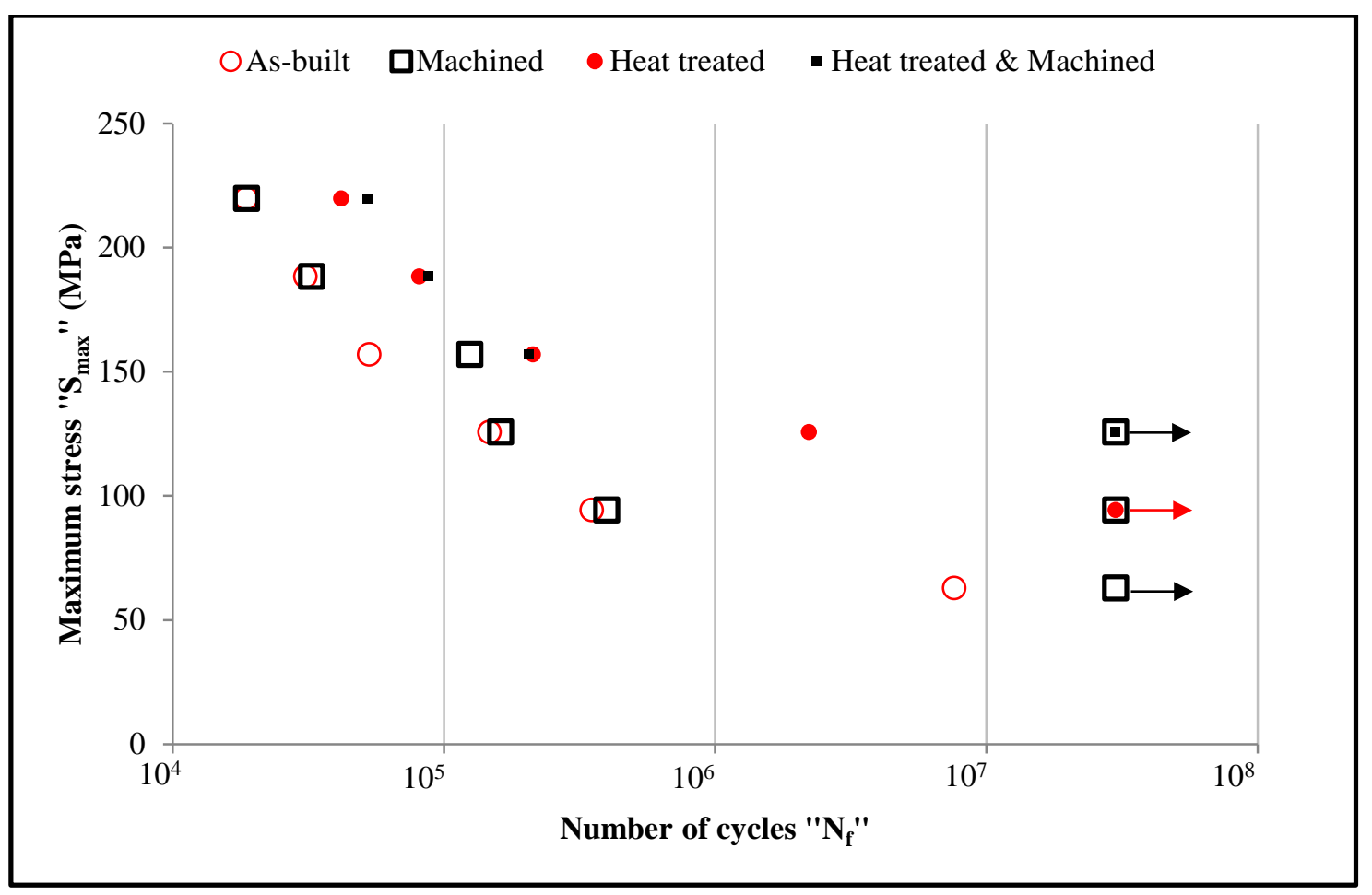

Figure 4: S-N curves superimposed for all the investigated conditions, namely, (1) as-built, (2) heat treated, (3) machined, and (4) heat-treated \& machined. Results on this plot are average values determined from three replicates at each data point.

Table 2: Basquin fit parameters for the fatigue data of samples with different conditions.

\begin{tabular}{lcc}
\hline \multicolumn{1}{c}{ Condition } & $\log (\mathrm{A})$ & $\mathrm{B}$ \\
\hline As-built & $2.92 \pm 0.09$ & $-0.22 \pm 0.02$ \\
Machined & $3.1 \pm 0.2$ & $-0.25 \pm 0.04$ \\
Heat-treated & $2.7 \pm 0.1$ & $-0.15 \pm 0.02$ \\
Machined \& Heat-treated & $3.1 \pm 0.1$ & $-0.25 \pm 0.02$ \\
\hline
\end{tabular}



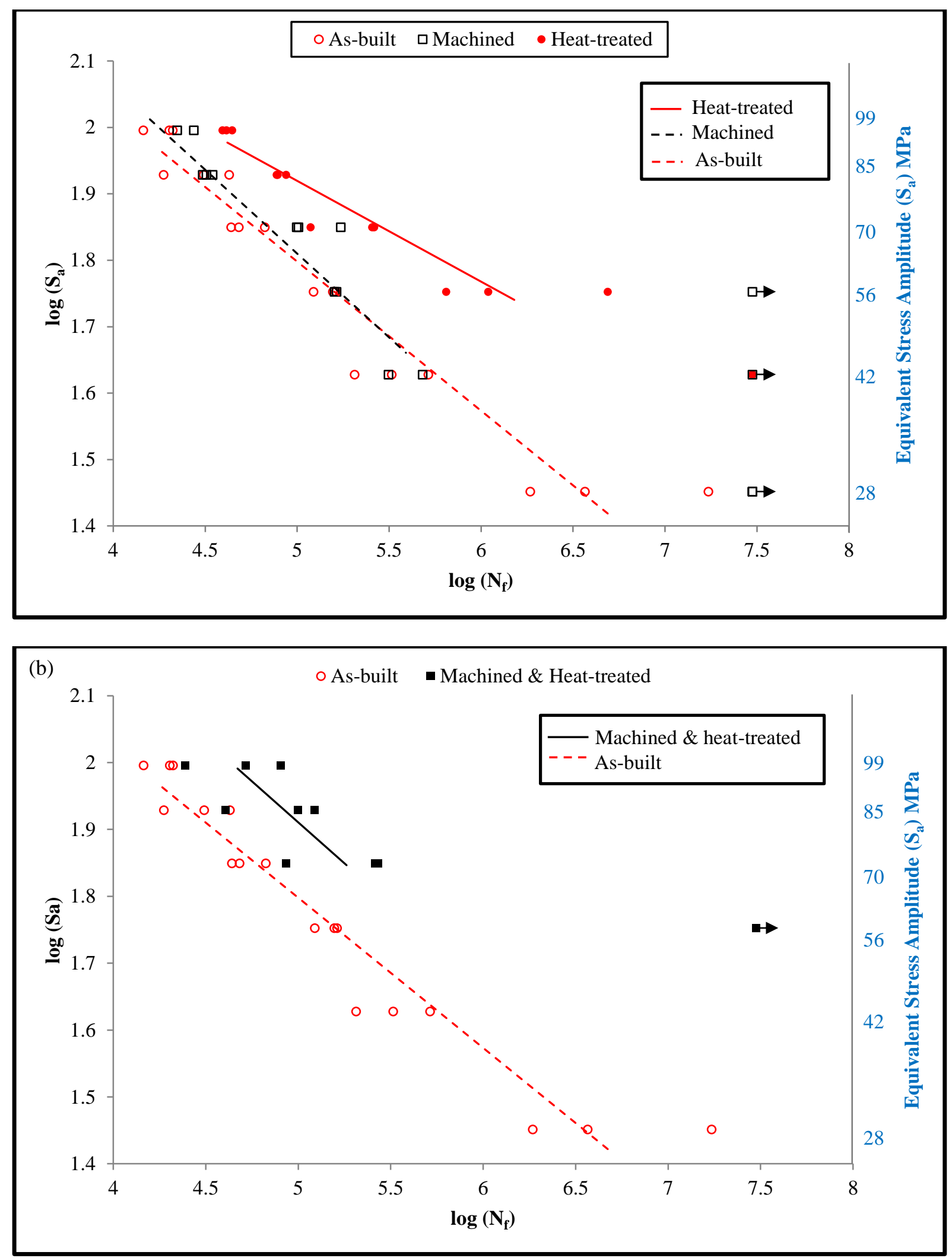

Figure 5: Effect of (a) machining and heat treatment, and (b) heat treatment followed by machining, on the fatigue behaviour of SLM AISi10Mg where " $S_{a}$ " denotes the nominal stress amplitude and " $N_{f}$ " denotes the number of cycles to failure. The data on these curves is fitted to a Basquin fit. 


\subsection{Fractography}

The fatigue fracture surface can be divided into three main zones that are (I) the cracked region where the crack initiates and grows slowly, (II) the steady propagation region, and (III) the final overload/fracture region where the crack propagation becomes fast leading to fracture. These regions are shown in the fractographs in Figure 6 and are developed through sub-structural and microstructural changes, formation of microscopic cracks, growth and coalescence of micro-cracks creating dominant cracks, crack propagation creating micro-cracks, and instability or complete failure [38]. Zone (I) is where a crack is first nucleated and it usually occupies a small area fraction of the fracture surface compared to the further stages of failure [39] at high stress levels, but its size increases with the decrease in stress level, as can be seen by comparing Figure 6 (a) and (b), which is common in cyclic loading [40]. At a nominal stress amplitude of $42 \mathrm{MPa}$, the radius of zone (I) was $2.5 \pm 0.2 \mathrm{~mm}$, whereas this radius decreased to $1.90 \pm 0.05 \mathrm{~mm}$ and $1.0 \pm 0.2 \mathrm{~mm}$ at nominal stress amplitude of $70 \mathrm{MPa}$ and $99 \mathrm{MPa}$, respectively. All the tested samples showed single crack origin irrespective of the stress applied. Figure 6 (c) shows that the crack propagated across the sample along a horizontal plane until zone (III) when the fracture surface shifted to a plane that is inclined to the flat surface by an angle of $45^{\circ}$, i.e. shear plane.

Fatigue striations on the fracture surface of the as-built sample can be seen in Figure 7 (a) and (b). The fatigue striations are features that are observed at the microscopic scale and each striation represents a cycle of fatigue crack propagation. The striations observed in the fracture surfaces of the as-built samples were brittle striations [39]. This brittleness could be attributed to the high residual stresses common in the SLM material [30] due to fast solidification. At high stress levels, such as the samples loaded at a $99 \mathrm{MPa}$ nominal stress amplitude, evidence of cleavage was observed in the final overload/fracture region. Failure in this region exhibited a fanlike appearance [40]. Examples are shown in Figure 7 (c) for the cleavage fans and lines. It was also noticed that the laser scan tracks used to process the samples could be observed on the fracture surface, as shown in Figure 7 (d). This, along with the cross-sectional view across the plane normal to the fracture surface in Figure 6 (c), suggests that the crack propagates along the interface between the melt pool boundary and core. 

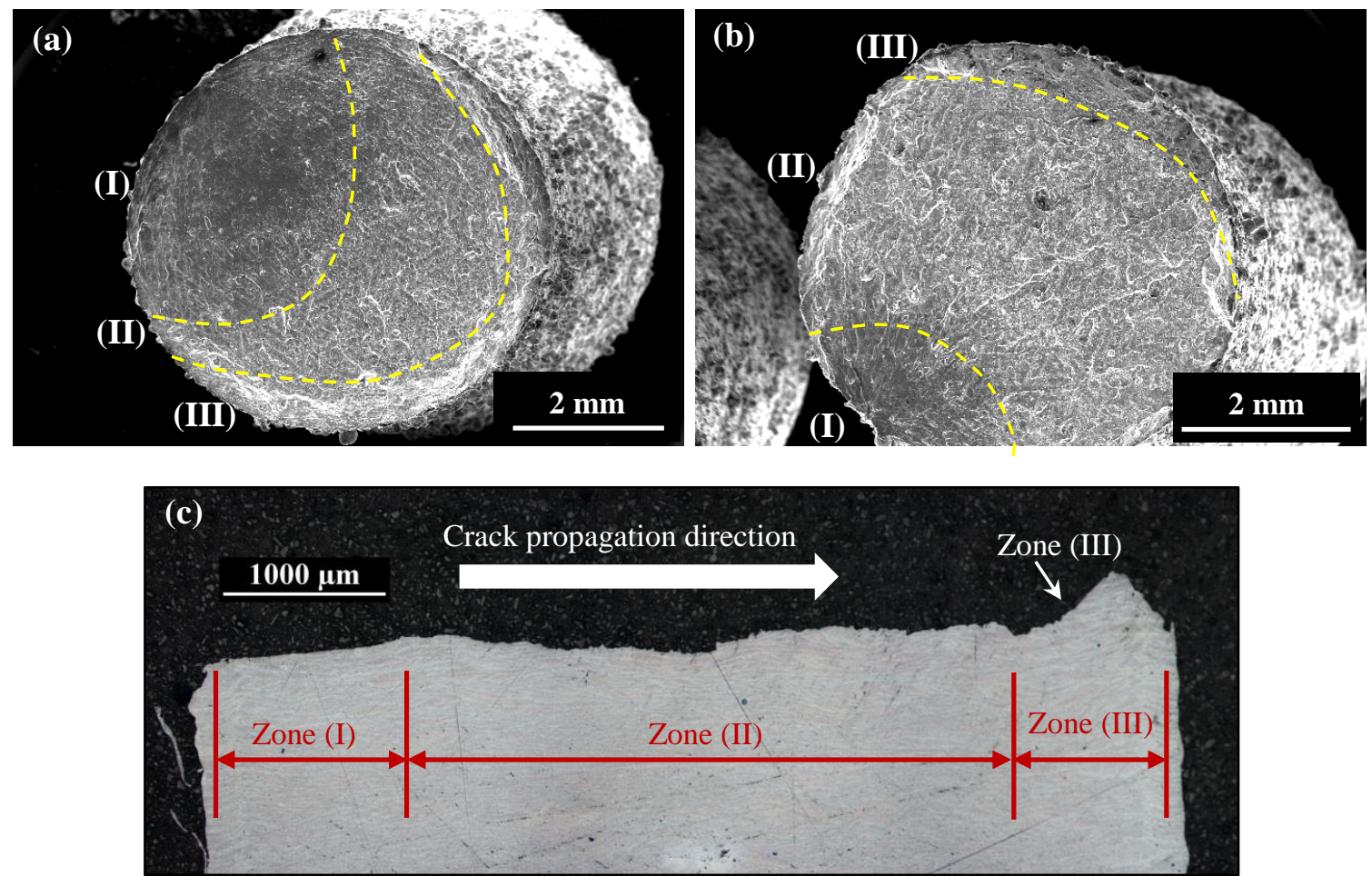

Figure 6: Zones of fatigue fracture in an as-built sample loaded by a maximum stress of (a) 94 MPa and (b) 220 MPa. (c) Cross-sectional view in a fracture surface as seen in the $\mathrm{XZ}$ plane.
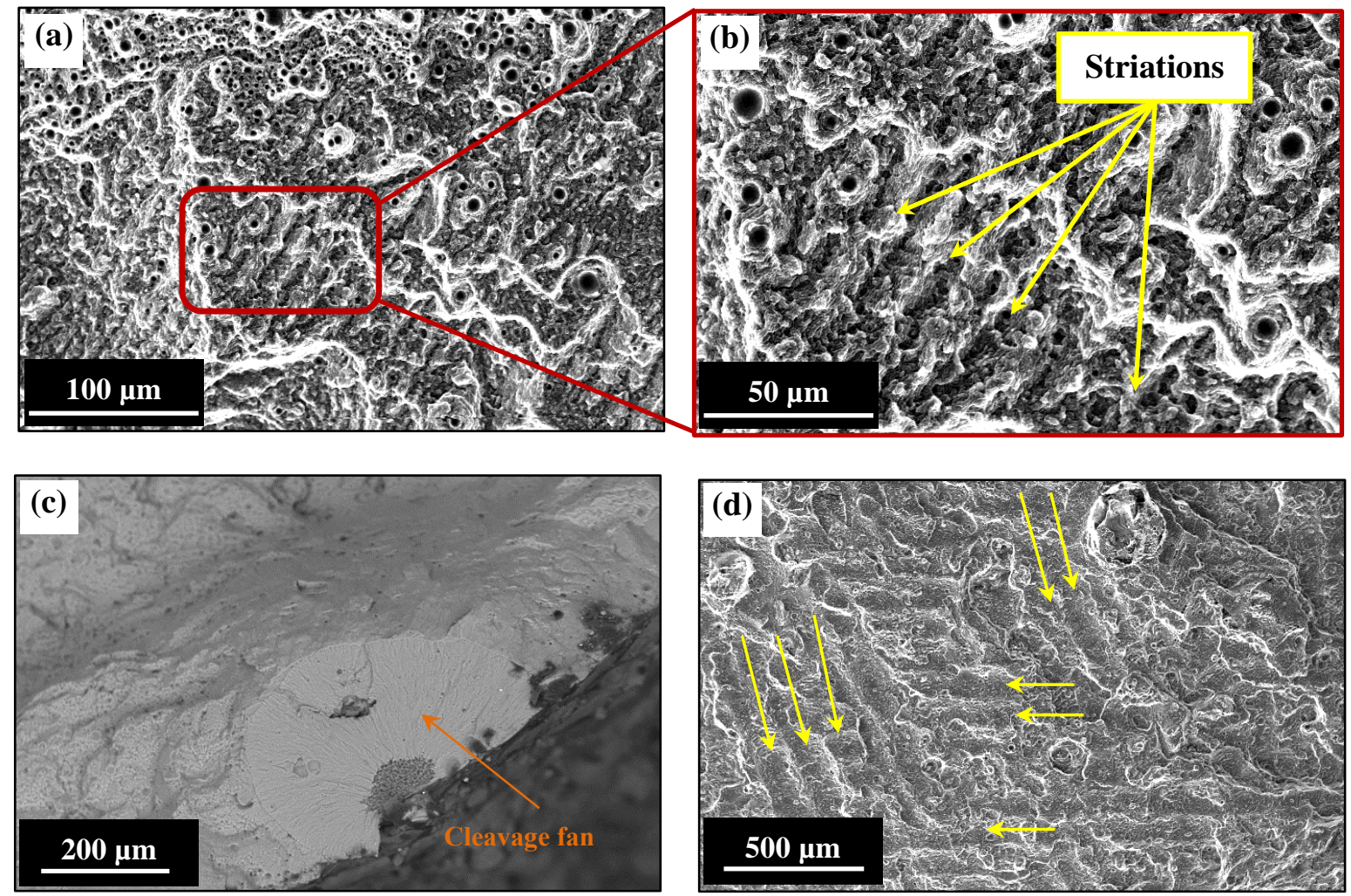

Figure 7: (a) and (b) Fatigue striations on the fracture surface of an as-built sample, (c) Cleavage fans and lines on the fracture surface of as-built samples tested at high stress levels, (d) The scan tracks building up the sample using the chessboard scan strategy clearly seen on the fracture surface of the as-built fatigue sample (indicated by the arrows). 
Some foreign particles of a spherical morphology were observed on some of the fracture surfaces, such as that shown in Figure 8. At point (A) in Figure 8, the relative chemical composition was $1.22 \mathrm{wt} \% \mathrm{Mg}, 12.96 \mathrm{wt} \% \mathrm{Si}$, and $80.55 \mathrm{wt} \% \mathrm{Al}$, whereas at point (B), the relative chemical composition was $0.37 \mathrm{wt} \% \mathrm{Mg}, 8.55 \mathrm{wt} \% \mathrm{Si}$, and $91.08 \mathrm{wt} \%$ Al. This composition as well as the spherical morphology suggests that this particle could be laser spatter. The laser spatter from this material was previously reported [17] to be rich in $\mathrm{Si}$ and $\mathrm{Mg}$ and this is in agreement with the energy dispersive X-ray diffraction (EDX) maps in Figure 8. Simonelli et al. [41] attributed the production of laser spatter during SLM to selective oxidation reactions. The presence of the laser spatter on the fracture surfaces of the fatigue samples indicates the importance of preventing their formation during processing, as they might become embedded in the final parts, contributing to a greater probability of failure under loading.
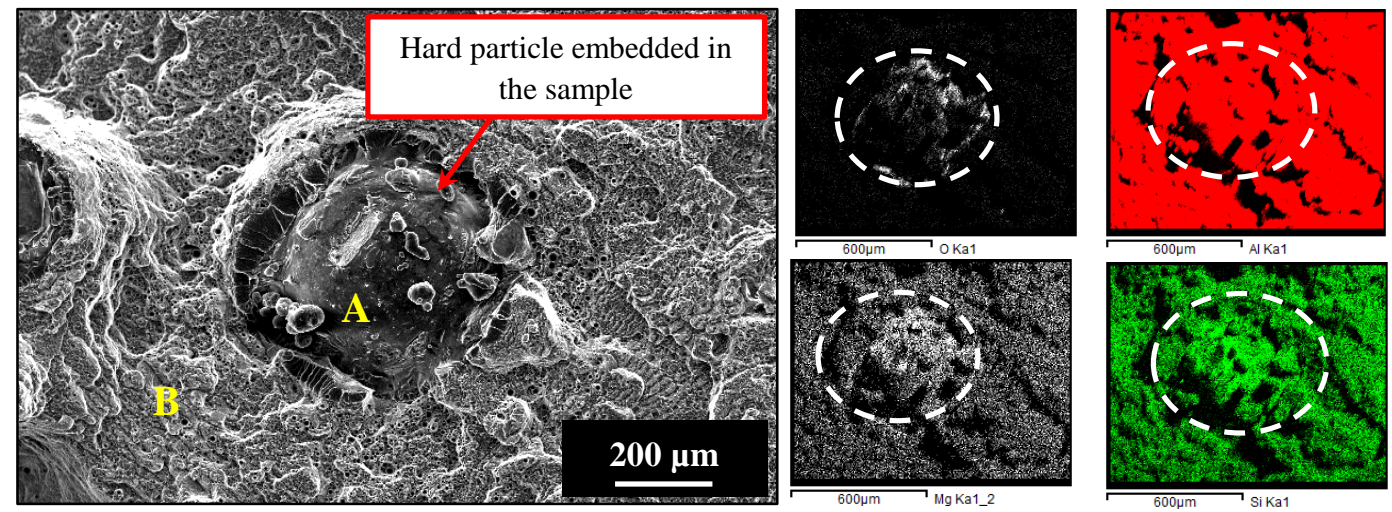

Figure 8: Foreign particle on the fracture surface a fatigue test specimen with EDX maps showing the particle rich in $\mathrm{Mg}, \mathrm{Si}$, and $\mathrm{O}_{2}$.

Fractography also showed that the machined samples failed due to surface defects, as shown in Figure 9. This was a consistent behaviour across all the samples. Closer investigation of the surfaces of the machined samples revealed pores that were originally sub-surface and surfaced by machining (Figure 9). This can explain why failure under cyclic loading for the machined samples still originated at the surface. Wycisk et al. [9] categorised the types of crack initiation under fatigue loading of SLM parts into two categories; (1) failure due to lack of fusion between the layers or (2) surface defect induced by the poor surface roughness in the as-built samples. The results in the current study support the second scenario, as was demonstrated in the fractographs that failure always originated at a surface or 
sub-surface defect (Figure 6 and Figure 9). Brandl et al. [15] have shown defects in SLM parts, either in the form of pores or non-melted spots, to cause stress concentrations and therefore reduce the strength. This is also in agreement Siddique et al. [42]. The susceptibility of failure under cyclic loading due to the presence of processing defects, such as pores, has also been previously reported for samples produced by electron beam melting [43].

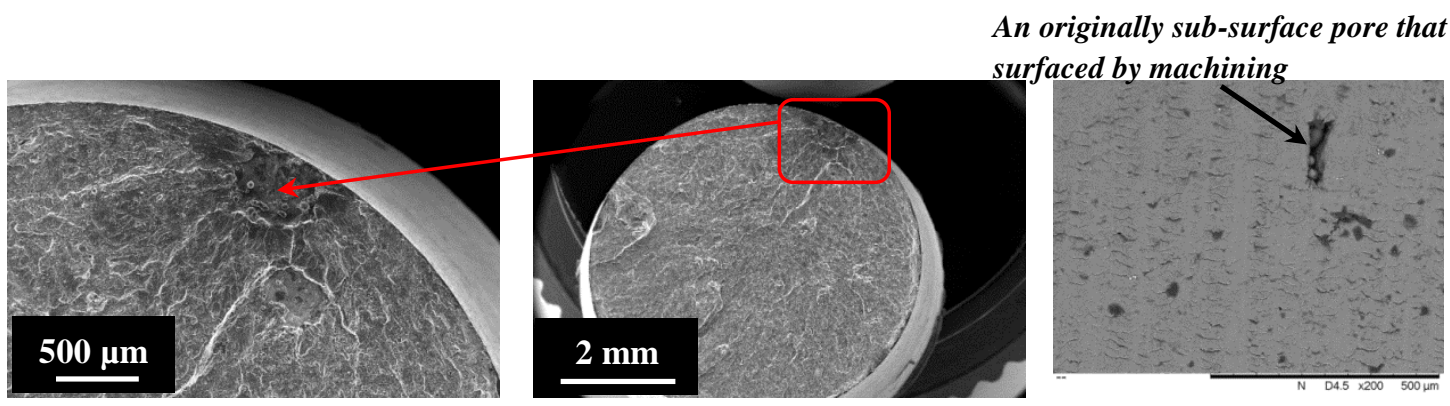

Figure 9: Fracture surface of a fatigue test specimen with machined surface showing failure to originate at a subsurface defect that probably was revealed by machining.

The effect of heat treatment on the fracture of the samples under cyclic loading is demonstrated in Figure 10. It is clear that the selected heat treatment leads to microstructural coarsening. Dimples appeared on the fracture surfaces of the heat-treated samples, which were not apparent in the as-built specimens, indicating increased ductility [15]. The ductile features on the surface of the heat-treated samples agree with the S-N curves presented earlier that demonstrated that the heat treatment improved the fatigue performance of the material since a material with higher ductility is less susceptible to fatigue crack initiation. A similar interrelation between a material's ductility and fatigue resistance was demonstrated by Kasperovich and Hausmann [29] for SLM Ti-6Al-4V.
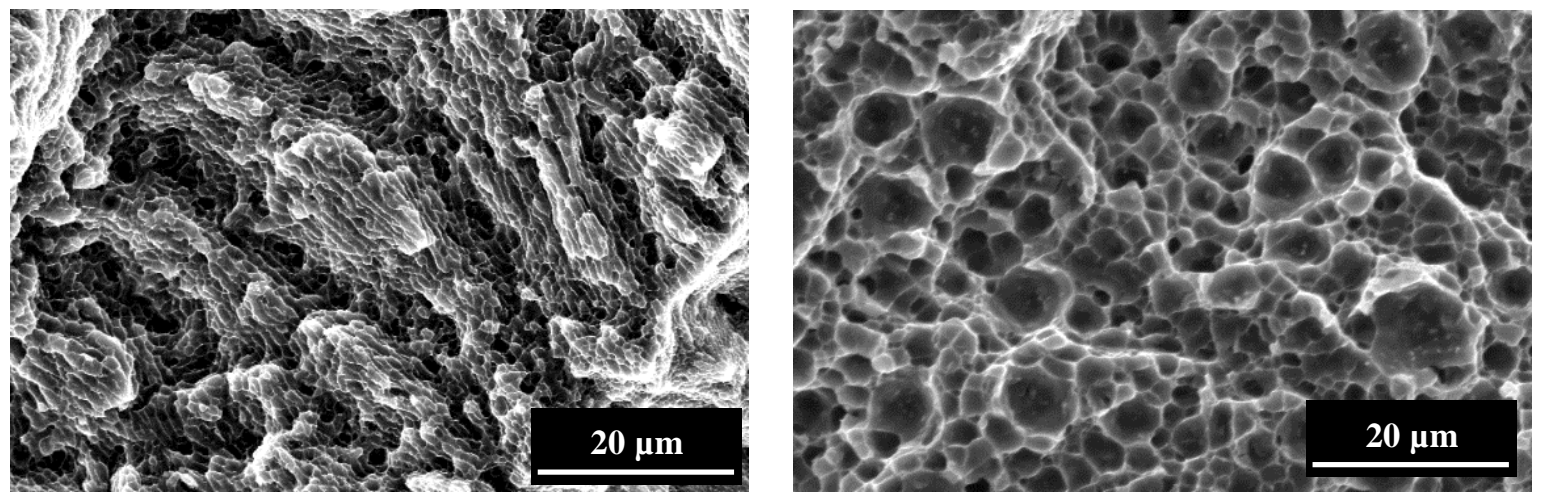

Figure 10: High magnification images for the fracture surfaces of (a) as-built and (b) heat-treated fatigue samples. 


\section{DISCUSSION}

The microstructure of the SLM material was seen to be finer at the melt pool core compared to the boundary. This is attributed to the latter region being at the interface between two melt pools, leading to slower solidification. When the liquid metal solidifies on a flat solid surface, unidirectional solidification is adopted rather than equiaxed solidification [44]. In the unidirectional solidification, the layer of the molten metal grows, forming crystals into cellular-like grains leading to dendrite formation. Conventional processing of AlSi10Mg, a hypo-eutectic alloy, results in an $\mathrm{Al}$ dendritic structure surrounded by inter-dendrite Al-Si eutectic. The form of Si changes according to the cooling rate, such as quench modification, thermal modification, or chemical modification [45]. Rapid cooling decreases the amount of $\mathrm{Si}$ ejected into the liquid by extending its solubility in $\mathrm{Al}$ [46], so a-Al solidifies first in the preferential cellular structure leaving the residual $\mathrm{Si}$ at the boundaries [47]. Coarsening of $\mathrm{Al}$ at the melt pool boundaries reduces the fraction of grain boundaries in this region, which means fewer sites for $\mathrm{Si}$ segregation. This is why the melt pool boundaries were rich in $\mathrm{Al}$ whereas the cores were rich in $\mathrm{Si}$ [31]. The presence of $\mathrm{Si}$ in AlSi10Mg is beneficial because it increases the alloy's fluidity [32], which enhances process-ability by SLM, and acts as a strengthening element to improve the mechanical properties, including performance under cyclic loading. However, as the Si content approaches the eutectic composition, its effect is inverted in the case of cast materials because at this point the Si forms platelets, which are sites favoured for fatigue crack nucleation [32]. This scenario however is not valid in case of the SLM material because of its distinctive microstructure in the as-built condition.

One of the downsides of SLM is the poor surface quality of the parts produced, either due to the formation of a surface with an irregular morphology or the presence of satellites or balling or surface porosity. This was clearly evident in the surface roughness measurements alongside the micrographs in Figure 2, where satellites adhering to the surface of a sample were seen. The poor surface quality of SLM parts can be a setback for the process as a net shape manufacturing technology since postfabrication processing may be needed to reduce the surface roughness. Although post-process machining might not be an issue for some parts, it will be difficult in cases where the geometry cannot 
be machined using conventional technologies. Examples are topology optimised parts and lattice structures, both of which are relevant in light-weighting. There are few studies in the literature covering the fatigue behaviour of SLM Al alloys; however, those available seem to have overestimated the surface quality as a factor. The results presented in this study disagree with this assumption to an extent, since machining the samples improved the fatigue performance only at lower stress levels (Figure 4). This contradicts results reported for other materials processed by SLM, such as Ti-6Al-4V [20] and 316L stainless steel [27]. It also shows that the difference in the fatigue performance of SLM AlSi10Mg samples in the work of Brandl et al. [15] with machined surfaces and those with as-built surfaces in the work by Mower and Long [28] cannot be solely attributed to surface quality. There are various factors that may have led to the poorer performance in [28] such as higher degrees of porosity. Failure of the samples always originated at surface defects in both as-built and machined samples. Although the machined samples did not suffer from the surface irregularities, surface pores were still observed since sub-surface pores in the as-built samples were exposed by machining, leaving the surface with defects that were susceptible to fatigue cracking. Generally, the parts produced using the optimised process parameters in this study yield parts with minimal porosity $(\leq 0.5 \%)$. The presence of these pores close to the surface increases the chance of revealing them by machining. The probability of this scenario is thought to be the reason behind the scatter in fatigue life data after machining. In this work, the heat treatment was the more significant contributor to enhancing the fatigue life at higher levels. This result means that a well-designed heat treatment procedure can significantly improve the fatigue performance of SLM AlSi10Mg parts without the need for post-processing machining for surface quality modification. This finding is in favour of SLM being a net shape manufacturing technology and is potentially attractive for industries interested in complex lightweight structures that cannot be machined post-processing. However, the combined use of heat treatment and machining improved the fatigue performance at all stress levels beyond the effect of solely heat-treating the samples or machining them.

Brandl et al. [15] attributed the improved fatigue strength in heat-treated SLM AlSi10Mg samples to the transformation of the $\mathrm{Si}$ dendrites to spheroids capable of hindering crack initiation and 
propagation. The crystallographic texture of a material has an influence on its fatigue behaviour, where a random texture means a softer material [38]. According to [22], the SLM material is one of a strong texture. The heat treatment has significantly altered the microstructure and randomized the microstructural texture because the evidence of directional solidification was eliminated. This, also, explains the enhancement in fatigue life via heat treatment. Moreover, based on the evolution in the material's hardness by heat treatment [31], it can be deduced that the conventional T6 heat treatment softens the material, i.e. increases the material's ductility, which means improved fatigue strength.

The results in this study were compared to data from the literature published by Brandl et al. [15] on the same alloy processed by SLM. The maximum stress at which the as-built samples in this study survived $10^{6}$ cycles was $\sim 102 \mathrm{MPa}$, whereas in [15] it was approximately $120 \mathrm{MPa}$. After heat treatment, the samples in [15] survived $10^{6}$ cycles at a maximum stress of around $170 \mathrm{MPa}$, whereas the samples in the current study were at a stress of 160 MPa. Bearing in mind that the heat treatment procedure Brandl et al. [15] used in their study involved significantly longer durations (solution heat treatment at $525^{\circ} \mathrm{C}$ for $6 \mathrm{hrs}$ followed by ageing for $7 \mathrm{hrs}$ at $165^{\circ} \mathrm{C}$ after water quenching), the results in this investigation therefore achieved a comparable behaviour while using shorter treatment durations. Results reported in [48] showed that cast samples from A356 treated using a T6 heat treatment survived $10^{6}$ cycles at a maximum stress of $\sim 139 \mathrm{MPa}$, indicating the superiority of the SLM heat-treated samples. The A356 is equivalent to AlSi7Mg, which is relatively close to the alloy in this study. This improved fatigue behaviour could be attributed to the finer microstructure, which means increased area of grain boundaries. Grain boundaries act as barriers to fatigue crack propagation, therefore, better fatigue crack propagation resistance can be achieved by refining the microstructure [49].

\section{SUMMARY \& CONCLUSIONS}

The as-built material in this study showed good performance under cyclic loading. Machining the samples did not enhance the fatigue life at higher stress levels but an enhancement was observed at the lower stress levels. On the other hand, heat treatment considerably improved the fatigue 
performance of the material. The optimum fatigue life was achieved when the samples were heattreated and machined. The enhancement in fatigue life via heat treatment was attributed to the induced ductility, microstructure transformation, and reduction of residual stresses. Failure under cyclic loading always originated at surface or sub-surface defects and propagated along the melt pool boundary, this being the weaker region since it is Al-rich. The significant improvement in the fatigue performance of the SLM AlSi10Mg through heat treating the samples with machined surfaces makes the material and process more attractive. Most importantly, demonstrating that heat treatment alone without surface machining can yield better fatigue performance, almost doubling the fatigue life, is a novel finding. This result is strongly appealing for industrial sectors interested in fabricating intricate structures using SLM with exceptional fatigue behaviour without the need for post-processing machining.

\section{ACKNOWLEDGMENTS}

Nesma T. Aboulkhair gratefully acknowledges funding provided by the Dean of Engineering Scholarship for International Research Excellence, Faculty of Engineering, University of Nottingham, United Kingdom. Thanks to Mr. Mark Hardy, Mr. Tom Buss, and Mr. Jason Greaves for their help with samples preparation and testing.

\section{REFERENCES}

[1] I. Yadroitsev, I. Smurov, Selective laser melting technology: From the single laser melted track stability to 3D parts of complex shape, Physics Procedia 5, Part B(0) (2010) 551-560.

[2] I. Yadroitsev, P. Bertrand, I. Smurov, Parametric analysis of the selective laser melting process, Applied Surface Science 253(19) (2007) 8064-8069.

[3] A. Aremu, I. Ashcroft, R. Wildman, R. Hague, C. Tuck, D. Brackett, The effects of bidirectional evolutionary structural optimization parameters on an industrial designed component for additive manufacture, Proceedings of the Institution of Mechanical Engineers, Part B: Journal of Engineering Manufacture (2013). 
[4] N. Gardan, Knowledge Management for Topological Optimization Integration in Additive Manufacturing, International Journal of Manufacturing Engineering 2014 (2014) 9.

[5] D.J. Brackett, I.A. Ashcroft, R.D. Wildman, R.J.M. Hague, An error diffusion based method to generate functionally graded cellular structures, Computers \& Structures 138(0) (2014) 102-111.

[6] C. Yan, L. Hao, A. Hussein, P. Young, D. Raymont, Advanced lightweight 316L stainless steel cellular lattice structures fabricated via selective laser melting, Materials \& Design 55(0) (2014) 533541.

[7] V. Matilainen, H. Piili, A. Salminen, T. Syvänen, O. Nyrhilä, Characterization of Process Efficiency Improvement in Laser Additive Manufacturing, Physics Procedia 56(0) (2014) 317-326.

[8] B.P. Conner, G.P. Manogharan, A.N. Martof, L.M. Rodomsky, C.M. Rodomsky, D.C. Jordan, J.W. Limperos, Making sense of 3-D printing: Creating a map of additive manufacturing products and services, Additive Manufacturing 1-4(0) (2014) 64-76.

[9] E. Wycisk, A. Solbach, S. Siddique, D. Herzog, F. Walther, C. Emmelmann, Effects of Defects in Laser Additive Manufactured Ti-6Al-4V on Fatigue Properties, Physics Procedia 56(0) (2014) 371378.

[10] D. Buchbinder, H. Schleifenbaum, S. Heidrich, W. Meiners, J. Bültmann, High Power Selective Laser Melting (HP SLM) of Aluminum Parts, Physics Procedia 12, Part A(0) (2011) 271-278.

[11] M. Seabra, J. Azevedo, A. Araújo, L. Reis, E. Pinto, N. Alves, R. Santos, J. Pedro Mortágua, Selective laser melting (SLM) and topology optimization for lighter aerospace componentes, Procedia Structural Integrity 1 (2016) 289-296.

[12] D. Dai, D. Gu, Thermal behavior and densification mechanism during selective laser melting of copper matrix composites: Simulation and experiments, Materials \& Design 55(0) (2014) 482-491.

[13] N. Read, W. Wang, K. Essa, M.M. Attallah, Selective laser melting of AlSi10Mg alloy: Process optimisation and mechanical properties development, Materials \& Design 65(0) (2015) 417-424.

[14] B. Song, S. Dong, P. Coddet, H. Liao, C. Coddet, Fabrication of NiCr alloy parts by selective laser melting: Columnar microstructure and anisotropic mechanical behavior, Materials \& Design 53(0) (2014) 1-7. 
[15] E. Brandl, U. Heckenberger, V. Holzinger, D. Buchbinder, Additive manufactured AlSi10Mg samples using Selective Laser Melting (SLM): Microstructure, high cycle fatigue, and fracture behavior, Materials \& Design 34(0) (2012) 159-169.

[16] V.D. Divya, R. Muñoz-Moreno, O.M.D.M. Messé, J.S. Barnard, S. Baker, T. Illston, H.J. Stone, Microstructure of selective laser melted CM247LC nickel-based superalloy and its evolution through heat treatment, Materials Characterization 114 (2016) 62-74.

[17] N.T. Aboulkhair, N.M. Everitt, I. Ashcroft, C. Tuck, Reducing porosity in AlSi10Mg parts processed by selective laser melting, Additive Manufacturing 1-4(0) (2014) 77-86.

[18] M. Shiomi, K. Osakada, K. Nakamura, T. Yamashita, F. Abe, Residual Stress within Metallic Model Made by Selective Laser Melting Process, CIRP Annals - Manufacturing Technology 53(1) (2004) 195-198.

[19] M. Leary, M. Mazur, J. Elambasseril, M. McMillan, T. Chirent, Y. Sun, M. Qian, M. Easton, M. Brandt, Selective laser melting (SLM) of AlSi12Mg lattice structures, Materials \& Design 98 (2016) 344-357.

[20] P. Edwards, M. Ramulu, Fatigue performance evaluation of selective laser melted Ti-6Al-4V, Materials Science and Engineering: A 598(0) (2014) 327-337.

[21] S. Leuders, M. Thöne, A. Riemer, T. Niendorf, T. Tröster, H.A. Richard, H.J. Maier, On the mechanical behaviour of titanium alloy TiAl6V4 manufactured by selective laser melting: Fatigue resistance and crack growth performance, International Journal of Fatigue 48(0) (2013) 300-307.

[22] L. Thijs, K. Kempen, J.-P. Kruth, J. Van Humbeeck, Fine-structured aluminium products with controllable texture by selective laser melting of pre-alloyed AlSi10Mg powder, Acta Materialia 61(5) (2013) 1809-1819.

[23] H. Gong, K. Rafi, H. Gu, G.D. Janaki Ram, T. Starr, B. Stucker, Influence of defects on mechanical properties of $\mathrm{Ti}-6 \mathrm{Al}-4 \mathrm{~V}$ components produced by selective laser melting and electron beam melting, Materials \& Design 86 (2015) 545-554.

[24] R. González, A. González, J. Talamantes-Silva, S. Valtierra, R.D. Mercado-Solís, N.F. GarzaMontes-de-Oca, R. Colás, Fatigue of an aluminium cast alloy used in the manufacture of automotive engine blocks, International Journal of Fatigue 54(0) (2013) 118-126. 
[25] Kwai S. Chan, Marie Koike, Robert L. Mason, T. Okabe, Fatigue Life of Titanium Alloys Fabricated by Additive Layer Manufacturing Techniques for Dental Implants, Metallurgical and Materials Transactions A 44(2) (2013).

[26] W.E. Frazier, Metal Additive Manufacturing: A Review, Journal of Materials Engineering and Performance 23(6) (2014) 12.

[27] A. Riemer, S. Leuders, M. Thöne, H.A. Richard, T. Tröster, T. Niendorf, On the fatigue crack growth behavior in 316L stainless steel manufactured by selective laser melting, Engineering Fracture Mechanics 120(0) (2014) 15-25.

[28] T.M. Mower, M.J. Long, Mechanical behavior of additive manufactured, powder-bed laser-fused materials, Materials Science and Engineering: A 651 (2016) 198-213.

[29] G. Kasperovich, J. Hausmann, Improvement of fatigue resistance and ductility of TiAl6V4 processed by selective laser melting, Journal of Materials Processing Technology 220 (2015) 202214.

[30] S. Siddique, M. Imran, E. Wycisk, C. Emmelmann, F. Walther, Influence of process-induced microstructure and imperfections on mechanical properties of AlSi12 processed by selective laser melting, Journal of Materials Processing Technology 221(0) (2015) 205-213.

[31] N.T. Aboulkhair, C. Tuck, I. Ashcroft, I. Maskery, N.M. Everitt, On the Precipitation Hardening of Selective Laser Melted AlSi10Mg, Metall Mater Trans A 46A(8) (2015) 3337-3341.

[32] R. González, D.I. Martínez, J.A. González, J. Talamantes, S. Valtierra, R. Colás, Experimental investigation for fatigue strength of a cast aluminium alloy, International Journal of Fatigue 33(2) (2011) 273-278.

[33] ASTM, E466-07 Standard practice for conducting force controlled constant amplitude acial fatigue tests for metallic materials, ASTM International, West Conshohocken, 2007.

[34] G.F.V. Voort, Metallography: Principles \& practice, ASM International United States of America, 1999.

[35] N.E. Frost, K.J. Marsh, L.P. Pook, Metal Fatigue, Dover Publications, United states of America, 1999. 
[36] N.T. Aboulkhair, I. Maskery, C. Tuck, I. Ashcroft, N.M. Everitt, On the formation of AlSi10Mg single tracks and layers in selective laser melting: Microstructure and nano-mechanical properties, Journal of Materials Processing Technology 230 (2016) 88-98.

[37] I. Maskery, N.T. Aboulkhair, C. Tuck, R.D. Wildman, I.A. Ashcroft, N.M. Everitt, R.J.M. Hague, Fatigue performance enhancement of selectively laser melted aluminium alloy by heat treatment, 26th Annual International Solid Freeform Fabrication Symposium, Austin, Texas, USA, 2015, pp. 1017-1025.

[38] S. Suresh, Fatigue of materials, 2nd ed., Cambridge University Press1998.

[39] J.C. McMillan, R.W. Hertzberg, Application of electron fractography to fatigue studies, American Society for Testing and Materials, Rashway, N. J., 1968.

[40] Charlie R. Brooks, A. Choudhury, Failure analysis of engineering materials, McGraw-Hill, United states of America, 2002.

[41] M. Simonelli, C. Tuck, N.T. Aboulkhair, I. Maskery, I. Ashcroft, R.D. Wildman, R. Hague, A Study on the Laser Spatter and the Oxidation Reactions During Selective Laser Melting of 316L Stainless Steel, Al-Si10-Mg, and Ti-6Al-4V, Metall Mater Trans A 46A(9) (2015) 3842-3851.

[42] S. Siddique, M. Imran, M. Rauer, M. Kaloudis, E. Wycisk, C. Emmelmann, F. Walther, Computed tomography for characterization of fatigue performance of selective laser melted parts, Materials \& Design 83 (2015) 661-669.

[43] X. Zhao, S. Li, M. Zhang, Y. Liu, T.B. Sercombe, S. Wang, Y. Hao, R. Yang, L.E. Murr, Comparison of the microstructures and mechanical properties of $\mathrm{Ti}-6 \mathrm{Al}-4 \mathrm{~V}$ fabricated by selective laser melting and electron beam melting, Materials \& Design 95 (2016) 21-31.

[44] D. Altenpohl, Aluminum viewed from within, Federal Republic of Germany, 1982.

[45] Aluminum: properties and physical metallurgy, American society for metals, Ohio, 1984.

[46] S.K. Bose, R. Kumar, Structure of rapidly solidified aluminium-silicon alloys, Journal of Materials Science 8(12) (1973) 1795-1799.

[47] K.G. Prashanth, S. Scudino, H.J. Klauss, K.B. Surreddi, L. Löber, Z. Wang, A.K. Chaubey, U. Kühn, J. Eckert, Microstructure and mechanical properties of Al-12Si produced by selective laser melting: Effect of heat treatment, Materials Science and Engineering: A 590(0) (2014) 153-160. 
[48] Q.G. Wang, D. Apelian, D.A. Lados, Fatigue behavior of A356-T6 aluminum cast alloys. Part I. Effect of casting defects, Journal of Light Metals 1(1) (2001) 73-84.

[49] Y.Q. Chen, S.P. Pan, M.Z. Zhou, D.Q. Yi, D.Z. Xu, Y.F. Xu, Effects of inclusions, grain boundaries and grain orientations on the fatigue crack initiation and propagation behavior of 2524-T3 $\mathrm{Al}$ alloy, Materials Science and Engineering: A 580(0) (2013) 150-158. 